\title{
Big data and big techs: understanding the value of information in platform capitalism
}

\author{
Alain Marciano ${ }^{1} \cdot$ Antonio Nicita $^{2} \cdot$ Giovanni Battista Ramello $^{3}$
}

Accepted: 4 November 2020 / Published online: 16 November 2020

(C) The Author(s) 2020

\begin{abstract}
One of the major challenges that result from the digital transformation occurring in our societies bears on its impact on the organization and regulation of the economy. This leads to a dramatic change to the economic institutions of capitalism-into what could be defined as platform capitalism - that rests on a fundamental dilemma between 'decentralization' on the one side and 'concentration' on the other. This is the main puzzle that the emergence of a big data driven economy is actually offering to law and economics scholars and to policy makers. This paper introduces to some of the major aspects of this dilemma.
\end{abstract}

Keywords Big data $\cdot$ Platform capitalism $\cdot$ Regulation $\cdot$ Decentralization · Concentration

\section{Introduction}

The digital revolution our societies are facing generates important challenges both at the level of the law and economics theory of institutions and at level of policy design. Big Data obviously transform the economic institutions of capitalism as we knew it into a sort of digital capitalism, changing the way in which information is produced and exchanged in the market. In a data driven economy, access to relevant information is dramatically decreased and so the dimension of transaction costs traditionally arising under various forms of asymmetric information, known as agency problems or post-contractual opportunism in incomplete contracts. Reduced transaction costs for accessing information are in turn expected to have an impact on the overall efficiency, reasonably positive, and to expand the

Giovanni Battista Ramello

giovanni.ramello@uniupo.it

1 University of Montpellier and MRE, Montpellier, France

2 Lumsa University, Roma, Italy

3 Università del Piemonte Orientale, Alessandria, Italy 
aggregate dimension of market transactions relative to hierarchical transactions within institutions alternative to the market (such us vertically integrated firms, according to Coase's (1981) and Williamson's lesson on the role of the dimension of transactions costs in affecting decisions on "make versus buy").

On the other hand, reduced transaction costs on gathering relevant information in the market (and on monitoring economic transactions and behaviors) also affect contracting costs over the bundle of uses embedded in private property rights. Many algorithmic solutions to rent a car or a house show as it has become easier and cheaper to coordinate actions and bargaining over access to each use included in the bundle of rights in a way that minimizes rival uses. One feature of the so-called 'sharing economy' precisely entails such characteristic of property rights divisibility for the uses bundled in a property right (Demsetz 1967): once non-separable, several uses bundled in a property right may now be allocated by data driven algorithmic decisions and by artificial intelligence, in new space and time dimensions, so as to increase joint-uses and thus to enhance the value of property rights.

All in all, in the big data economy, reduced transaction costs of accessing information are increasing the potential for improved efficiency, in terms of increased room for market transactions. This process implies that we should expect decentralized transactions to grow, i.e. more market, less hierarchy.

At the same time, and somewhat for the same reasons, we would expect a growing size of algorithmic mediated transaction also for decisions in the public or juridical sphere: an example is the use of big data, artificial intelligence and algorithmic profiling in courts, as well as the adoption of blockchain technology to perform duties previously delegated to judges or public officials (notaries, lawyers and so on) (Ashley 2017; Medvedeva et al. 2020; Katz et al. 2017).

However, the actual pattern in the global data driven economy is much more complex than one would expect. Indeed, the potential for 'decentralization' (in terms of the expected increase in the dimension of market transactions relative to hierarchical 'vertical' control) is actually coupled with a strong tendency toward market concentration, with the emergence of new global players acting as 'platform intermediaries', in multi-sided markets, precisely thanks to their ability in extracting and managing big data, through successful algorithmic processes. It seems as if the positive externalities generated by the reduction of transaction costs are actually appropriated by these big intermediaries rather than being released to the market as a public good.

This dilemma between 'decentralization' on the one side and 'concentration' on the other is the main puzzle that the emergence of a big data driven economy is actually offering to law and economics scholars and to policy makers.

The efficiency of platforms increases due to network effects and the value of data collected-which in turns improves the efficiency of algorithms and consumers' welfare (in terms of reducing transaction costs). Thus, for a platform to be efficient, the expansion of the service's scope and the extension of the markets served will be a natural evolutionary process, aimed at capturing a consumers' attention and time under the promise of satisfying all their needs, through the platform's gatekeeper role. 
As a consequence-under business as usual, i.e. absent any focused regulatory action-the spontaneous evolution of market forces will lead soon to structural changes in the traditional (and often locally based) vertical industry dynamics, inducing competition among (few) platforms for (many) global markets.

This ongoing process has already raised many policy questions, sometimes driven by partisan attitudes pro or anti-platforms such as among others: do we care about this paradigmatic shift from traditional to digital (platform based) capitalism? Shall we apply traditional antitrust criteria and regulatory approaches to digital platforms, and their dominance over well-defined relevant product markets? Shall we instead change our perspective, given the benefits to consumers, who often pay lower (or even zero) prices for products and services implicitly exchanged for "attention"? Shall we consider big data a new entry barrier for many digital markets ${ }^{1}$ Shall we consider privacy-based inalienability rules for personal data or shall we build (and stimulate) a competitive market for data, even by defining clear property rights on our own data ("propertisation")? ?

The debate is open and only at the begininnigs. Answers are complex as they entail many interdisciplinary dimensions at the intersection among antitrust, privacy, basic rights, free choice and communications regulation. One of the main points behind the debate concerns the relationships among platforms, big data and algorithms, as the value and impact of big data could not be properly assessed without taking into account the business model of the main digital platforms (and the apps downloaded by internet users), which, in turn, is based on the value and impact of algorithms. Machine learning processes require a large amount of data to improve their performance. This is the main reason why efficient global platforms need a large amount of big data to improve their predictive ability and implicitly exchange (zero priced) services for users' data. Moreover, the efficiency of algorithms improves the matchmaking performance of the platforms over multisided markets, offering users "what they want", but also helping programmatic advertisers to properly reach a segmented and profiled audience. What is more since prefrences are sometime malleable and psychological issues may affect consumer's choice, as a long-lasting tradition has discussed in law and economics, they may also perturbe the freedom of choice. ${ }^{3}$

The economic challenge here is how to provide good and efficient governance of the transition between the old and the new world.

The laissez faire approach to platforms simply suggests that the evolution of digital capitalism should be governed by new (very light) rules (Evans and Schmalensee 2016). This means abandoning old paradigms (such as notions of dominance, market power, relevant market, monopolisation and so on) that would otherwise affect platforms at their core, as they would treat as "behaviour" what is, after all, just a business model performing both allocative and distributive efficiency-as consumers'

\footnotetext{
1 Ref. e.g. Rubinfeld and Gal (2017).

2 Ref. among others Curry (2016) and Acquisti et al. (2015).

3 This issue has been introduced many decades ago by Guido Calabresi in the law and economics debate (see Marciano and Ramello 2014). The current system might enhance the conundrum.
} 
obtain a larger amount of services (included many traditional services offered by non-platform providers) at lower costs.

On the opposite side, a prudential approach, based on the precautionary principle, contrasts the "new nirvana" of platform-based capitalism, on the basis of the social hidden costs in terms of monopolisation and "monopsonisation" of affected markets (included the job market), generated by these new global intermediaries, thanks to their ability to gather, control and exclusively use personal data (Stucke and Grunes 2016; Becker 2019).

\section{Information and big data in the free market paradigm}

The tension between the above two approaches could be summarized by referring to the economic notion of "externality", i.e. of the indirect economic effect generated by production or consumption and that does not pass through an explicit pricedriven market exchange. Platforms manage and enjoy positive externalities, such as the voluntary "implicit" exchange of personal data by platform users. However, platforms also generate negative externalities on many traditional industries whose demand is actually redirected towards the platforms' (zero) priced services. Moreover, by intermediating among many sided markets, matchmaking by platforms is able to extract a large amount of (informational) rents by any side. This means that platforms increase efficiency-in terms of reduced transaction costs-but also that they actually keep for themselves a large portion of the (informational) rents extracted from participants to the multisided markets intermediated by platforms.

As a consequence, this "structural efficiency" of platforms may raise new puzzles over the laissez faire approach. Laissez faire policies are generally based on the classical idea that free markets perform well and better comparatively to other (governmental or privately based) hierarchical or command-and-control institutions. But also that market does not suffer of failures that might come from structural imperfections or rent seeking behaviors.

In genera free market meet the efficiency criterion when strong competition among participants occur that obliges economic agents to publicly reveal their private information. As a consequence, under well-functioning markets, information is free, accessible and "observable" to all. On the contrary, in platform-based capitalism, "revealed" (personal) information by platform users is privately kept by the matchmaker. Access to a wide volume and scope of personal data is precisely the source of platform's competitive advantage over competitors and supremacy over consumers. It is thus puzzling, under the laissez-faire approach, how to reconcile, in a unified theoretical framework, the standard social benefits of free markets with the emergence of new global intermediaries, such as online platforms, whose main feature is that of preventing the gathered private information from being publicly revealed in the open market.

A second pillar of the laissez-faire approach is the central role of the agents' freedom to choose (both on demand and supply side). However, the hidden side of platforms' network effects (according to which consumers' benefit of using a platform grows as long as the platform increases its dimension) is that they also constitute 
consumers' opportunity costs to switch toward an alternative platform. That means, in turn, that platform capitalism may weaken consumers' incentives to switch, thus inhibiting one of the central mechanisms of competition in free markets: free choice among alternative offers. Again, how is it possible, for the laissez-fair approach, to reconcile in a unified framework, the benefits of free markets with the emergence of significant exit costs on platforms' users?

To properly understand the value of big data in digital capitalism, a step back is thus needed into our understanding of the value and role of information as an economic good in well-functioning (or perfectly competitive) markets (Schiller 2000; Stiglitz 1985). Information is, on the one side, an essential input for well-functioning markets and, on the other, it is their worthy outcome. Competitive markets are efficient (relative to any other alternative institution) when they are able to convey otherwise dispersed information, on both the supply and demand sides, into 'public' signals such as price and quantity, that reduce search costs and allow the optimal allocation of economic resources (Douglas and Holt 1996; Farrell and Klemperer 2006). As a consequence, markets' (allocative) efficiency relies on the value of the information publicly released.

The information is an economic good, and moreover, in well-functioning markets, it is a public good, being non-excludable and non-rival in consumption, thus freely accessible. When information is private, or asymmetric, a market failure does emerge, leading to the so-called agency problems, namely moral hazard and adverse selection: the market fails in performing its allocative efficiency, precisely because information is private, so that other institutional or contractual arrangements are needed to let economic agents reaching second best outcomes.

Now, two main efficiency paradoxes do emerge when considering the way in which digital platforms extract, gather and use information: (i) the privatisation of public good information through big data extraction; (ii) the informational capture of platforms' users through algorithmic profiling.

These are efficiency paradoxes as they are on one hand the result of platform efficiency, but, on the other, they weaken the two main pillars of well-functioning markets: the efficiency of information as public good and the role of consumers' freedom to choose as a competitive discipline device.

\section{Big data as privately held information by platforms}

The first efficiency paradox for the datasphere society is that its core value relies on big data that is, indeed, privately held information, i.e. a situation whose persistence would generate a market failure. Big data could eventually be accessible by many (depending on the nature of data), but, in platform capitalism, it seems not to be managed as a public good information. Indeed, algorithm-based platforms extract personal data through the implicit exchange between the product/service and users' attention, or any other form of personal information that allows users' profiling. These large amounts of data are public in nature, however, and de facto private as only platforms are entitled to keep this data, generally for business purposes, even if through vertically integrated uses. 
This is a paradox as long as it shows that the "efficiency of the platform"-based on cumulating the private information extracted from users-contrasts with the "efficiency of the market"-based on revealing to all public information otherwise dispersed and privately owned. Platforms reduce transaction costs in the form of search costs but only within the platform, while the efficiency of markets, in terms of search costs reduction, shall not be limited to specific firms or organisations as it shall generally spread to all the economic agents participating in the competition game.

This is the reason why, from an economic point of view, it is hard to reconcile under a unified framework the "efficiency of the market" with the "efficiency of the platform": markets and global platforms differ structurally in terms of the nature, public or private, of the information extracted from consumers. In turn, this affects the meaning and extent of allocative efficiency: for a platform keeping private the information gathered from users to perform the same level of allocative efficiency of the market, that platform has to become "the market", i.e. it has to expand its activities to entirely cover all the sides of the market.

If our analysis is correct, then the normal efficient outcome of an expanding platform, focused on managing big data, should be as a monopolistic/monopsonistic platform acting as the sole matchmaker. Thus, one should conclude that the overall efficiency in platform capitalism has to be coupled with competition for (being) the market, rather than with competition within the market.

This is not entirely new. In classical economic theory, Adam Smith and Leon Walras, named respectively the Invisible Hand and the Auctioneer, the ideal and stylized matchmaker allowing dispersed information in the market to meet in equilibrium between demand and supply at selling prices equal to marginal costs of production. However, both the Invisible Hand and the Auctioneer were fictitious intermediaries, "as if" metaphors designed to figure out the functioning of the markets when dispersed private information comes to be public thanks to the mechanism of free competition. On the contrary, actual global platforms are matchmakers that privately hold and exclusively keep the information they gather. This information, also through an opportunistic interpretation of privacy laws, is not shared with rivals or any another "anonymous stranger" in the market.

In our view, this is a paradox to the extent to which the emergence of platforms is generally depicted as a natural consequence of market competition in the digital ecosystem: global platforms, naturally emerging in free markets, generate indeed, a 'fundamental transformation' in the nature and role of knowledge and information through the "privatisation" of big data extracted from users. Dynamic efficiency here, absent any form of regulation, is thus coupled with a natural evolution towards monopolization or, at best, towards the Edward H. Chamberlin's old notion of 'monopolistic competition' (however under a very limited number of competing platforms).

Moreover, when the platform's informational rents refer to exclusive use of big data, gathered by the platform - and, due to the dimension of the platform, this process generates scarcity in access to relevant information-then, according to some scholars, big data could, in principle, be envisaged as a sort of new essential facility whose access is necessary to enter the relevant markets (Rubinfeld and Gal 2017). 
However, the process of monopolisation by a digital platform, on the other hand, does not necessarily mean that competition is out, for at least two main reasons. First, because competition might be "a click away", as drastic innovation may substitute existing platforms with new entrants, as happened with Yahoo versus Google or Nokia versus Apple and Samsung, and so on. Second, because some kind of big data (the so-called structured data) could be easily replaced by alternative and competing platforms, so that the platform's informational rents generated by cumulating exclusive big data could easily vanish. Thus, in this case, one should ask whether the competitive advantage of the platform relies on having exclusive access to "scarce" big data or on being able, through the development of powerful algorithms, to use efficiently big data even when they are easy to replace and to lock-in a significant amount of platform's users.

Nonetheless, even when easily replaceable, privately held big data could constitute a barrier to entry in some other circumstances, increasing the opportunity cost for switching platforms. In these cases, the barriers to entry are given by the users' exit costs, in terms of opportunity costs to leave the old platform to the new one. The bigger the platform, the higher would be the opportunity costs (i.e. in terms of losing the positive network externalities present in the incumbent platform) to leave it. This means, in turn, that the dimension of the existing platform plays a role also on the demand side. As the efficiency of algorithms depends on the dimension of big data treated, the combination of privately held big data, dimension of the platforms, network externalities and users' exit costs, may ensure the enduring persistence of a platform against new entrants' competitive challenge, because of demand's inertia in switching platforms, together with the users' coordination costs needed to efficiently switch (Farrell and Klemperer 2006).

\section{Users' exit costs and informational aftermarkets}

A second efficiency paradox is the platform's ability to make discrimination strategies (price and non-price), thanks to user profiling allowed by data extraction, while weakening consumers' freedom to choose out of the platform. ${ }^{4}$

Standard microeconomic theory suggests that there are forms of discrimination that increase allocative efficiency, because they enable consumption of goods and services by consumers willing to pay not less than the marginal cost of production. This also applies to indirect forms of discrimination that take place through bundling of services and products, at least in those cases where consumer preferences are negatively correlated for the different bundle's elements. However, it is well known that some forms of discrimination are inefficient as they may negatively affect competition. This happens when price discrimination is implemented at upstream level by vertically integrated companies controlling an essential resource; or when the

\footnotetext{
4 On the law and economics of big data and discrimination see in particular Botta and Wiedemann (2020) and Gautier et al. (2020) in this same issue.
} 
discrimination is selectively practiced by a dominant firm towards groups of contestable consumers.

The problem with digital platforms arises when the discrimination is allowed by the extraction of exclusive informational rent by the new data profilers in the digital ecosystem. This is not so much a classical matter of privacy or data protection, but due to the fact that the consumer ends up being screened from the competition and placed in a kind of informational after-market in which the expression of needs and market transactions become one-to-one relationships rather than one-to-many. Under "perfect profiling", the consumer loses incentives to even search for alternatives, as the platforms may understand, foresee and satisfy, in due time, any potential need.

Under exclusive access to big data, the informational capture (and hence the informational rent gained) by the incumbent platform could be such to prevent any attempt by consumers to search for market alternatives (also because search activity is often known by the incumbent platform). This process increases endogenously the incumbent platform's market power vis à vis competing platforms as well as its bargaining power vis à vis final users.

This means that perfect profiling powered by consumers' inertia and behavioural biases, fosters laziness, along with the paradox that the digital world of search becomes its opposite and creates happy and inert consumers.

Under an informational aftermarket, consumers continue to choose freely, but by means of customised menus and within the platform environment. It is true that these menus might be the "best choice" for the consumer (as the platform "knows" what the user wants). Nonetheless, under customisation, the degree of comparability among platforms by the user may get increasingly difficult. Hence, the paradox here is that a platform's efficiency may well satisfy a final user who lacks ability and even a chance to exert free choice among alternatives. If this is true, platform efficiency in profiling may generate the "end of the markets" and of the competition dynamics, that will be replaced by cluster powered by consumers' informational capture.

Of course, this might be a rather bleak picture in which, there is no room for disruptive innovations, generated by competitive pressure, and resulting in a limitation of the dominant positions. However, the point is that the magnitude of this potential outcome may depend on the degree of informational capture and the actual constraints to the consumers' rational and free choice among alternatives. The universe of markets, under this vision, sooner or later may fall into small star systems in which the consumers will only be able to observe what orbits very close around them, indeed exercising their "free" choice though in a non-market context.

Today it is impossible to know if the prophecy of traditional markets, swallowed up by the digital capitalism black hole, will come true or not. The risk of informational capture, under exclusive use of big data, and the creation of informational aftermarkets, raise significant issues in this respect.

A lateral paradox is that some privacy rules, as long as they increase transaction costs over the development of a free market for big data may even exacerbate 
the above risks, by imposing the platform to exclusive use (i.e. not to share with third parties) the big data gathered from users.

\section{The role of data portability}

Two possible exit strategies against the above risks are big data access and sharing, and consumers' management of property rights over own data. The first strategy is contrasted by the fact that it seems quite complex to define big data as an essential facility tout court. The second strategy has gained strong support in the General Data Protection Regulation (GDPR) in Europe. ${ }^{5}$

The EU data protection legal framework ensures that personal data can only be gathered under strict conditions and for legitimate purposes and are protected from misuse. In particular, personal data must be:

- Processed lawfully, fairly and in a transparent manner

- Collected for specified, explicit and legitimate purposes

- Adequate, relevant and limited to what is necessary in relation to the purposes for which they are processed

- Accurate and, where necessary, kept up to date

- Kept in a form which permits identification of the person to whom the information is related for no longer than it is necessary

- Processed in a manner that ensures appropriate security and protection, e.g. against unauthorised or unlawful processing, accidental loss, or destruction or damage.

In January 2017, the European Commission adopted a proposal to modify the e-privacy directive12 and adapt the sector specific legislation to the GDPR.13 Key points of the proposal are:

- The application of privacy rules to new players providing electronic communications services (e.g., WhatsApp, Facebook Messenger and Skype)

- Privacy is guaranteed for communications content and metadata, e.g. time of a call and location, which must be kept in an anonymous form or deleted if users did not give their consent

- Simplification and streamlining of rules on cookies

- Protection against unsolicited electronic communications (spam), e.g., by default or using a do-not-call list; marketing callers will need to be identifiable

- The enforcement of the confidentiality rules will be the responsibility of data protection authorities already in charge of the rules under the GDPR.

\footnotetext{
5 Regulation (EU) 2016/679 of the European Parliament and of the Council available at https://eur-lex. europa.eu/legal-content/EN/TXT/HTML/?uri=CELEX:32016R0679\&from=EN\#d1e3265-1-1.
} 
One of the main novelties regards the user's right to the portability of their own data when switching provider. The real impact of this measure needs to be tested, but it constitutes a principle that goes in the right direction of:

- Defining property rights on personal data (protected by property rules) 14

- Setting new default rules in digital transactions, by re-directing bargaining power over data use in favour of platform's users,

- Allowing an effective freedom to choose on users' platforms

- Restoring, through freedom to choose, a degree of workable competition among platforms.

\section{Understanding the impact of (private) value of big data on competition}

Data portability works well when a competitive market for big data is well-functioning. One of the main conditions for a market to work is to have well-defined property rights, high transparency and publicly revealed information. Economic agents should be aware of what they exchange and about the value of what is exchanged.

But what are the private and market values of personal data? The answer is not trivial. The Italian Telecommunication and media regulator (Agcom) carried out an econometric analysis on the apps available in Google Play revealing that there is a statistically significant negative relationship between the number of privacy licences signed by users on the use on their data by the app, and the price users are willing to pay for downloading the app (Agcom 2018). At the same time, on the supply side, app producers and sellers fix the price of the app on the basis of the number of licences they require users to sign. As a consequence, even if-according to a survey conducted by the same Agcom-only $60 \%$ of users are actually aware of the implicit exchange of personal data when they download apps or have access to a digital platform, there is a market value behind the implicit exchange of personal data against digital services and products.

In our view, policymakers and regulators will need to make it explicit to consumers and platform users the existence of a market for personal data, allowing the consumer to choose how to sell and to whom this data, using this bargaining power also as a mechanism device to enhance competition among platforms. Data portability, in this respect, is just one first step in the right direction.

Big Techs have been extensively rewarded and chosen by consumers because of their innovative services and ability to meet consumers' preferences and needs, yet they also gained a tangible power to influence markets, competitive dynamics and consumers' welfare. There are two opposite economic and policy visions about the impact of Big Techs on markets and competition. On the one side, they are (quasi) natural monopolies, because of economies of scale and scope, the direct and indirect network effects and the essential (data) assets they benefit, implying the need of a regulation and/or a competition policy approach similar to (other) network industries. On the other, there is adequate (potential) competition in the market(s), mainly for the market(s), as market power in digital world is temporary, because incumbent 
companies are subject to Schumpeterian displacement by more innovative new entrants (as it was the case for Myspace overtaken by Facebook, Yahoo by Google, Netscape by Microsoft Explorer).

Probably, both these 'extreme' visions suffer some forms of path dependency: both are based on incremental and marginal extension of the economic thinking and policy approaches adopted for (analogue) telecoms and media markets. Undoubtably, there are crucial economic entanglements and very relevant trade-offs involved in defining a policy for platforms, mainly between the static and dynamic market value of information 'created' and services provided by digital platforms on the one side, and the respect of individual and collective fundamental rights (e.g., privacy, competition, consumers' rights and media pluralism), on the other.

This polarised policy visions are also a consequence of a 'limited regulatory capacity' suffered by public bodies, which didn't allow regulators (namely, telecoms and data protection) and competition authorities to designed a public intervention tailored on the specific economic, business, and technical characteristics of digital undertakings and consumers. ${ }^{6}$ Solutions found, such as "wait and see", "business as usual" or "self-regulation", do not represent effective policy and regulatory instruments, at least not by themselves, and indeed did not build an effective governance for new digital markets and the new social interactions that digital platforms create.

In a nutshell, the limited regulatory capacity has origin in two main elements: (i) a profound information asymmetry between public bodies and the great players of the digital world, where it is in fact very difficult for regulators to "push" digital actors to reveal relevant information both on their internal technical functioning (the algorithms of the platforms are from the outside real "black boxes") and on the economic dynamics of the global digital markets; (ii) public policies and powers are traditionally designed and implemented at national (or continental) level, while digital and platform economies have global nature and features, which associated to the virtual context manage to escape from public rules tangles.

In the ongoing debate, there is an extremely difficult trade-off of unprecedented complexity between the risk of an intrusive intervention, hampering innovation and economic value created by digital platforms, and the risk of allowing digital giants to consolidate and exploit market power. Policy makers and ex-ante regulators have been struggling to understand how to proceed and firstly how to approach the existing economic entanglements and trade-offs related to digital platforms. However, in this context, a clear, comprehensive and advanced regulatory policy has been designed and put in place in Europe with regards to data protection (GDPR). Yet, there are widespread doubts about the effectiveness of an approach where ex-ante regulation is limited to a narrow, yet extremely important, aspect, such as data protection. Moreover, embracing a regulatory approach to data limited to data protection implies evident tension with pro-competitive policy objectives, as

\footnotetext{
${ }^{6}$ Even though all sectors are affected by this epochal phenomenon, Telecommunications and Media are at the very forefront of this transition as electronic communication networks represent the "backbone" of digital ecosystem and because very often services provided by digital platforms have a high degree of substitutability with traditional communication, information and audio-visual services.
} 
data protection rules in general tends to limit access to data, which is crucial (if not essential asset) for competition in the digital markets, notwithstanding data portability provisions. As it usually happens in (disruptively) evolving market context, competition law enforcement has taken the lead on public intervention, mainly because of its enforcement flexibility and ability to adapt to new market circumstances. The most relevant recent (since 2012) competition law cases for big tech at EU level over the last few years concerned cases of abuse of dominant position (under articles 102 TFEU): 3 subsequent cases involving Google, i.e., Search Shopping (2017), Android (2018), AdSense (2019) and one case involving Amazon about e-book 2 (2017) and an ongoing investigation about Amazon use of retailers data. Moreover, still very relevant were few merger cases Facebook/WhatsApp (2014), Microsoft/LinkedIn (2016).

Nevertheless, competition law enforcement in digital markets has been perceived by many to be slow compared to market dynamics, and often limited to clear cases of foreclosure where a dominant platform leverages its market power on another (downstream or upstream) market (i.e., all Google cases), but not really tackling the actual digital market problems and market failures which are often not (only) those of market power, consequently not preventing crucial and market detrimental mergers (e.g., Facebook/WhatsApp and Microsoft/LinkedIn). Moreover, although big techs have global dimension and enormous economies of scale regarding supply and demand, it remains always quite difficult to identify which are the targeted relevant markets, given the nature of the intermediaries among more markets and more sides. Moreover, in many cases it is problematic to identify a consumer harm, and antitrust intervention are very stretched in this sense, as the main economic characteristic of digital platforms, e.g. network effects, zero-price models and productive efficiency (reduction of search and transaction costs) provide immediate and tangible benefits to consumers.

\section{Conclusions}

Platform capitalism is based on exclusive access to big data and on platforms' ability to capture final users through efficient algorithmic profiling. "It's all about data", but as platforms' efficiency and barriers to entry both grow with platforms' dimension, regulators and policymakers will raise the issue of dynamic efficiency in a world where information is not anymore a public good in open markets and where consumers' inertia reduces incentives to switch platforms.

The debate is open and the increasing awareness of the implicit value of personal reveals that new policy approaches are starting from consumers' empowerment over the use and sale of own data.

Placing the platform user at the centre of the digital transaction on their own data implies giving centrality also to the issue of the appropriability and portability of the profiled data. This would enhance the user's ability to recover their own bargaining and contractual power towards the platform, also by participating in the profitability generated by the digital transactions. 
In turn, data ownership and portability, on consumer's side, strengthens a user's freedom to choose among alternative platforms, while reducing the competitive advantage of incumbent platforms' exclusive access to big data.

Based on these arguments, there has been a world-wide intense public policy debate on how to tackle the overall competitive and market/consumer issues in digital platform economy and what policy tools, i.e., regulatory, antitrust, consumer protection and data protection, would be best suited to address those trade-offs concerning data and platforms economy. Indeed, as happened in the electronic communications sector, it seems that an effective approach could result from competition law enforcement sketching pro-competitive policy lines, to be then 'codified', made coherent and received by an ex-ante regulatory legislation. Moreover, in this context, the activities of the Competition and Market Authorities, Telecoms Regulators and Data Protection Agencies are often interplaying and have in some respects substitutable or complementary field of action. Therefore, not only new substantial provisions have been discussed, but also possible reforms on the institutional and enforcement setting. However, as happened for electronic communications, a note of caution should be paid toward a complete internalisation of the competition principle in the regulatory framework. As a matter of fact, a complete convergence of regulation toward competition law principle and tool could lead to situation where market failures other than market power, cannot be approached in the right way, as happened for termination and international roaming which needed centralised regulation exogenous to the regulatory framework; and could also lead to the dynamic dialogue between different regulatory objectives, i.e., promotion of competition and investment /innovation, which needed to be progressively adjusted. Indeed, any regulation of digital markets must consider the main aspects of on-line platform economics, that is (a) the establishment of a business model based on global digital transactions, where data is implicitly exchanged for free services in a multi-sided market context, and (b) the ability of reaching efficient outcomes similar to a perfect competition context, but_-differently from perfect competition-obtained by internalising and exploiting information about preferences and willingness to pay of each customer. Indeed, what is positive under a productive-efficiency perspective may lead consumers to make their choices in smaller and smaller markets, finally tailored on each consumer. This phenomenon, jointly with indirect and direct network externalities, can lock users in an "information digital aftermarket", where gatekeepers, administrating consumers' information and selecting each user's services, products and prices, looks more and more not like companies yet like "markets". This outcome may not well be desirable from a competitive and social point of view.

Funding Open access funding provided by Università degli Studi del Piemonte Orientale Amedeo Avogrado within the CRUI-CARE Agreement.

Open Access This article is licensed under a Creative Commons Attribution 4.0 International License, which permits use, sharing, adaptation, distribution and reproduction in any medium or format, as long as you give appropriate credit to the original author(s) and the source, provide a link to the Creative Commons licence, and indicate if changes were made. The images or other third party material in this article are included in the article's Creative Commons licence, unless indicated otherwise in a credit line to the 
material. If material is not included in the article's Creative Commons licence and your intended use is not permitted by statutory regulation or exceeds the permitted use, you will need to obtain permission directly from the copyright holder. To view a copy of this licence, visit http://creativecommons.org/licen ses/by/4.0/.

\section{References}

Acquisti, A., Brandimarte, L., \& Loewenstein, G. (2015). Privacy and human behavior in the age of information. Science, 347(6221), 509-514.

Agcom. (2018). Big data Interim report in the context of the joint inquiry on "Big data" launched by the AGCOM deliberation No. 217/17/CONS. https:/www.agcom.it/documents/10179/10875949/Alleg ato+4-9-2018/f9befcb1-4706-4daa-ad38-c0d767add5fd?version=1.0.

Ashley, K. (2017). Artificial intelligence and legal analytics: new tools for law practice in the digital age. Cambdrige: Cambdrige University Press.

Becker, J. (2019). The antitrust paradigm Restoring a competitive economy. Cambridge: Harvard University Press.

Coase, R. H. (1981). The firm, the market, and the law. Chicago: Chicago University Press.

Curry, E. (2016). The big data value chain: definitions, concepts and theoretical approaches. In: Cavanillas JM, et al. (eds) New horizons for a data-driven economy. New York: Springer.

Evans, D. E., \& Schmalensee, R. (2016). Matchmakers: the new economics of multisided platforms. Massachusetts: Harvard Business Review Press.

Farrell, J., Klemperer, P. (2006). Co-ordination and lock-in: competition with switching costs and network effects. In: Armstrong M, Porter RS (eds) Handbook of industrial organization, vol. III. North-Holland.

Katz, D., Bommarito, M., \& Blackman, J. (2017). A general approach for predicting the behavior of the Supreme Court of the United States. PLoS ONE. https://doi.org/10.1371/journal.pone.0174698

Medvedeva, M., Vols, M., \& Wieling, M. (2020). Using machine learning to predict decisions of the European Court of Human Rights. Artificial Intelligent Law, 28, 237-266.

Rubinfeld, D.L., Gal, M.S. (2017). Access barriers to big data. Arizona Law Review 59(2).

Schiller, D. (2000). Digital capitalism Networking the global market system. Cambridge: MIT Press.

Stiglitz, J. (1985). Information and economic analysis: a perspective. Economic Journal, 95(suppl), $21-41$.

Stucke, M. E., \& Grunes, A. P. (2016). Big data and competition policy. Oxford: Oxford University Press.

Publisher's Note Springer Nature remains neutral with regard to jurisdictional claims in published maps and institutional affiliations. 